\title{
ANÁLISE DE UMA PROPOSTA COLABORATIVA DE FORMAÇÃO CONTINUADA DE PROFESSORES DE CIÊNCIAS NA PERSPECTIVA DO DESENVOLVIMENTO PROFISSIONAL DOCENTE
}

\author{
Analysis of a collaborative continuing teacher education \\ proposal in science for the professional development \\ of teachers
}

Fabiana Cardoso Urzetta ${ }^{1}$. Ana Maria de Oliveira Cunha ${ }^{2}$

Resumo: Este artigo relata resultados de uma pesquisa de mestrado do Programa de Pós-Graduação em Educação da Universidade Federal de Uberlândia, na qual se buscou compreender a possibilidade de desenvolvimento profissional, por meio da análise de uma proposta coletiva de formação continuada de professores de Ciências, que se configurou em uma ação de caráter colaborativo entre universidade e escola. Analisou-se, ainda, o potencial do envolvimento entre professores da Educação Básica e pesquisadores da Universidade, na transformação da prática docente. A opção metodológica situou-se nos domínios da abordagem qualitativa, na sua modalidade de Estudo de Caso do tipo etnográfico. A análise dos dados apontou que a profissão docente e o seu desenvolvimento profissional constituem elemento fundamental para assegurar a qualidade do processo ensino-aprendizagem, e a necessidade de que o desenvolvimento profissional seja concebido como um processo coletivo e colaborativo, consistindo em possibilitar, aos professores, a construção de novas teorias e práticas pedagógicas.

Palavras-chave: Desenvolvimento profissional. Formação continuada de professores. Ensino de ciências.

\begin{abstract}
This article reports results of a research Master's Graduate Program in Education at the Federal University of Uberlandia, which aimed to understand the possibility of professional development through the analysis of a continuing education conference for science teachers, which was set up collaboratively between university and school. It also analyzed the potential involvement of teachers of Basic Education and University researchers in the transformation of teaching practice. The methodology had a qualitative approach, and used ethnographic case studies. The data analysis indicated that for the teaching profession, professional development is key to delivering a quality teachinglearning process and the need for professional development can be conceived as a collective and collaborative process, allowing teachers to construct new theories and pedagogical practices.
\end{abstract}

Keywords: Professional development. Continuous formation of teachers. Science teaching.

\footnotetext{
${ }^{1}$ Prefeitura Municipal de Uberlândia, Escola Municipal Professor Domingos Pimentel de Ulhoa, Uberlândia, MG. Rua Antônio Zeferino de Paula, 865, Bairro Santa Mônica, CEP 38408-270, Uberlândia, MG, Brasil. Email: <fabianaurzetta@hotmail.com>

${ }^{2}$ Universidade Estadual de Uberlândia (UFU), Instituto de Biologia, Campus Umuarama, Uberlândia, MG, Brasil.
} 


\section{Introdução}

Este texto relata resultados de uma pesquisa de mestrado do Programa de Pós-Graduação em Educação da Universidade Federal de Uberlândia, que teve como objetivo investigar a possibilidade de desenvolvimento profissional, por meio da análise de uma proposta coletiva de formação continuada de professores de Ciências do Ensino Fundamental. A experiência investigada se configurou em uma ação de caráter colaborativo entre docentes da Rede Municipal de Ensino, professores pesquisadores dos conteúdos específicos e pedagógicos da Universidade Federal de Uberlândia e alunos da graduação e pós-graduação. A opção metodológica situou-se nos domínios da abordagem qualitativa na modalidade de Estudo de Caso do tipo etnográfico, na qual buscamos compreender como a aproximação do docente da Educação Básica com professores pesquisadores da Universidade facilita a articulação entre teoria e prática, e como essa proposta pode possibilitar a reflexão e a transformação da prática docente dos professores envolvidos.

$\mathrm{Na}$ presente investigação, procedemos a uma análise dos principais paradigmas que norteiam os processos formativos, bem como sobre os pressupostos teóricos e legais sobre a formação continuada de professores, incluindo as novas tendências e desafios nessa perspectiva.

Analisamos os dados obtidos por meio de questionários, observações e entrevistas semiestruturadas, à luz dos referenciais teóricos disponíveis na literatura sobre formação docente (CANDAU, 2007; IMBERNÓN, 2002; NÓVOA, 1992; SCHNETZLER, 1996; SCHÖN, 1997; TARDIF, 2002; ZEICHNER, 1993, entre outros), buscando apresentar as reflexões sobre as experiências vivenciadas pelos professores de Ciências na proposta de formação continuada pesquisada.

Partimos do pressuposto de que a formação do professor é um processo que não se finaliza com a formação inicial; ao contrário, impõe-se, como fundamental, a formação continuada, em que as reflexões sobre práticas profissionais se tornem a base desse processo, no qual, a formação deve ser o resultado da vivência teórica e prática, de forma que o docente possa tecer alternativas para o seu desenvolvimento profissional.

\section{Formação continuada de professores: construindo conhecimentos}

A formação continuada, em sentido amplo, é entendida como processo ininterrupto que acompanha o professor durante toda a sua trajetória profissional, e, em sentido estrito, como forma deliberada e organizada de aperfeiçoamento, que o incentive, pela ação, pela reflexão e pela interação com seus pares, ao aprimoramento de sua prática e à apropriação de saberes rumo à autonomia profissional (FALSARELLA, 2004).

Segundo Candau (2007), a preocupação com a formação continuada de professores não é uma novidade, afirmando que a mesma está presente em todos os esforços de renovação pedagógica que, geralmente, são promovidos pelos sistemas de ensino. As políticas educacionais incidem fortemente sobre o docente, como protagonista privilegiado do processo educacional, e, sendo assim, a qualificação de professores, para melhorar a qualidade da Educação, tem de ser acompanhada por políticas que garantam: a reorganização da estrutura administrativa, a valorização dos professores, a disponibilidade de recursos financeiros e materiais, e o planejamento participativo. 
Nos textos da legislação brasileira, podemos observar o destaque conferido à formação continuada dos professores, porém, parece ainda haver uma abertura para a consolidação da formação continuada como trocas de "receitas", metodologias e técnicas instrumentais, numa perspectiva de formação baseada no paradigma da racionalidade técnica. Essas trocas também são importantes, mas reafirmamos que a formação continuada deveria ser um espaço de reflexão crítica, coletiva e constante sobre a prática de sala de aula, desenvolvimento da atitude de cooperação e corresponsabilidade, avaliação do trabalho e replanejamento.

A formação continuada de professores, segundo Schnetzler (1996), justifica-se pela necessidade de contínuo desenvolvimento profissional, de reflexões críticas sobre a própria prática pedagógica e de superação do distanciamento entre as contribuições da pesquisa educacional e sua utilização para a transformação da prática docente.

Imbernón (2002) concebe a formação docente como um processo de desenvolvimento profissional, que tem início na experiência escolar e prossegue ao longo da vida, incluindo questões relativas a: salário, carreira, clima de trabalho, estruturas organizacionais, níveis de participação e de decisão.

$\mathrm{Na}$ literatura mais recente, temos encontrado o conceito de desenvolvimento profissional docente em substituição ao de formação inicial e continuada (IMBERNÓN, 2002; MARCELO, 2009; NÓVOA, 2008). A preferência por essa conceituação é justificada por Marcelo (2009), porque define, claramente, a concepção de profissional do ensino; e o termo desenvolvimento profissional sugere evolução e continuidade, rompendo com a tradicional justaposição entre formação inicial e continuada. Assim, o desenvolvimento profissional docente é entendido como um processo, que pode ser individual ou coletivo, mas que deve se contextualizar no local de trabalho do docente - a escola -, e que contribui para o desenvolvimento das suas competências profissionais por meio de experiências de diferentes características, tanto formais como informais.

Alguns autores, conforme observa García (1999), referem-se à formação continuada de professores como toda atividade que o professor realiza com uma finalidade formativa, tanto de desenvolvimento profissional como pessoal, individualmente ou em grupo, para um desempenho mais eficaz das suas tarefas atuais ou que o preparem para desempenhar novas funções. García (1999) entende o desenvolvimento profissional como o conjunto de processos e estratégias que facilitam a reflexão dos professores sobre a sua própria prática e contribuem para a geração de conhecimento prático, estratégico, e lhes possibilitam aprender com a sua experiência. Desse modo,

O conceito de desenvolvimento profissional docente pressupõe uma abordagem na formação de professores que valorize o seu caráter contextual, organizacional e orientado para a mudança. Esta abordagem apresenta uma forma de implicação e de resolução de problemas escolares a partir de uma perspectiva que supera a característica tradicionalmente individualista das atividades de aperfeiçoamento dos professores. (GARCÍA, 1999, p. 137)

Assim é que, objetivando a melhoria e o aperfeiçoamento do corpo docente, as secretarias estaduais e municipais de Educação se empenham, significativamente, na elaboração e 
na implantação de programas de formação continuada com investimentos financeiros e humanos substanciais.

Candau (2007) questiona o tipo de concepção de formação continuada presente nesses programas e indaga se, neles, há o predomínio de uma concepção dicotômica entre teoria e prática, em que à Universidade corresponde a produção do conhecimento e, aos professores da Educação Básica, a sua aplicação, socialização e transposição didática.

Temos, historicamente, convivido com essa lógica, na qual os supostos saberes da prática advêm de teorizações de pesquisadores que nem sempre consideraram as especificidades da mesma. Assim, o que chega ao educador é um saber produzido e legitimado por outro. Todavia, quando o professor articula o saber pesquisado com a sua prática, ele interioriza outra lógica, que passa a atribuir mais significado ao saber-fazer docente.

Até a década de 1990, promovia-se, no País, uma formação de professores voltada para a questão técnica e política do trabalho pedagógico, para o método e o conhecimento teórico do conteúdo, restringindo-se a ações de aperfeiçoamento dos conteúdos e técnicas de ensino, desenvolvidas em palestras, seminários, oficinas, isto é, eventos pontuais e descontínuos, desvinculados da prática docente. Essa abordagem, como pontua Nóvoa (1997), reduzia a profissão docente a um conjunto de técnicas, gerando uma crise de identidade dos professores em decorrência da separação entre o eu profissional e o eu pessoal. Nesse modelo,

São apresentadas abordagens de ensino ou tratados conteúdos específicos (para tentar sanar as deficiências da formação inicial) com o propósito de os professores aplicarem em suas salas as ideias e propostas que a academia considera eficazes. Além de conceber erroneamente a formação continuada, tais ações mantêm o professor atrelado ao papel de "simples executor e aplicador de receitas" que, na realidade, não dão conta de resolver os complexos problemas da prática pedagógica. (SCHNETZLER, 2000, p. 23)

O fato de não acreditarmos na eficácia de cursos de curta duração para promover mudanças no pensamento do professor não significa que eles devam ser abolidos. Eles podem representar momentos desencadeadores da reflexão do professor sobre a sua prática, determinando novas buscas, mas, para isso, seu planejamento deve estar voltado para esse objetivo. Como afirma Nascimento (2008), não se pode deixar de considerar a importância de algumas dessas ações e os ganhos que elas podem proporcionar. Entretanto, é importante salientar que, por serem esporádicas, essas intervenções não atendem a projetos globais de formação docente e, normalmente, estão voltadas mais para os interesses do sistema do que para a valorização pessoal e social dos professores.

A partir do ano de 1996, por meio dos estudos de teóricos como Nóvoa (1992), Schön (1997) e Zeichner (1993), a formação dos professores encontra suporte na teoria do professor reflexivo, contrariando a visão tradicional a respeito da prática educativa. A formação continuada passa a ter como perspectiva a reflexão dos professores sobre suas próprias práticas. Conforme esses autores, há um reconhecimento de que a formação também ocorre com a prática docente, ressaltando-se a valorização dos saberes experienciais no processo de 
formação. É na comparação, no apoio e nas trocas com os pares que pode ser construído um conjunto de saberes necessários à sua formação e ao fazer-se professor.

Nóvoa (1992) reforça, ainda, que a formação docente não se constrói por acumulação de cursos, de conhecimentos ou de técnicas, mas sim, por meio de um trabalho de reflexividade crítica sobre as práticas e de (re) construção permanente de uma identidade profissional.

\section{$O$ contexto da pesquisa: a proposta vivenciada}

A partir do repensar uma prática docente de cunho transformador e reflexivo, foi vislumbrada uma proposta de formação continuada, por professores do Curso de Ciências Biológicas da Universidade Federal de Uberlândia (UFU), em que, por meio de uma parceria colaborativa entre Universidade e Educação Básica, a distância entre dois universos fosse minimizada.

A formação de parcerias, implicando a discussão de contribuições das pesquisas em Educação em Ciências que, ao serem confrontadas com descrições, problemas e características das práticas pedagógicas usuais dos professores de Ciências, contribuam para que estes, gradativamente, reformulem suas práticas. Tal processo certamente será mais eficaz se for realizado coletivamente (SCHNETZLER, 1996).

Inicialmente, a referida proposta foi divulgada aos professores das escolas públicas das redes municipal e estadual de ensino de Uberlândia, por meio de cartas, e-mails, ida às escolas e aos encontros de professores da Rede Municipal de Ensino.

A proposta iniciou-se em agosto de 2008 e, no primeiro momento, foi realizada uma reunião geral na Universidade Federal de Uberlândia, com a participação de todos os envolvidos, para uma apresentação geral das suas especificidades e das concepções formativas que nortearam a sua elaboração, bem como de seus objetivos e do provável cronograma de ações. Nesse primeiro encontro, foram feitas explanações sobre a importância da formação continuada e sobre o paradigma do professor pesquisador, como um dos focos de trabalho da proposta. A seguir, os professores pesquisadores apresentaram suas linhas de pesquisa, dentro das quais os professores presentes se inseriram, constituindo seis grupos temáticos: Biologia Animal, Biologia Celular e Corpo Humano, Biologia Molecular, Biologia Vegetal, Ecologia e Educação Ambiental.

Nos meses de setembro a dezembro de 2008, foram realizados encontros quinzenais em cada grupo temático, buscando a construção coletiva da proposta em ações específicas para cada área, iniciando-se, assim, um processo de discussão e consolidação dos grupos, em que foram envolvidos: professores de Ciências do Ensino Fundamental, professores pesquisadores de conteúdos pedagógicos e específicos da área de Biologia, vinculados aos Institutos de Biologia, de Ciências Biomédicas e de Genética e Bioquímica da Universidade Federal de Uberlândia, graduandos e pós-graduandos.

Dificuldades foram encontradas para o prosseguimento da proposta, como a frequência irregular dos professores e a ausência de um espaço físico adequado para as reuniões. No início de 2009, demos continuidade à proposta, contando com a parceria da Secretaria Municipal de Educação, por meio do Centro Municipal de Estudos e Projetos Educacionais (CEMEPE) e da coordenação da área de Ciências da Rede Municipal de Ensino. Essa parceria 
possibilitou infraestrutura adequada e participação mais efetiva de professores de Ciências da Rede Municipal. Os encontros passaram, então, a acontecer no espaço físico desse centro de estudos e, também, nos laboratórios da Universidade Federal de Uberlândia.

Inicialmente, foram realizados encontros gerais, com a participação de todos os professores inscritos, bem como os professores pesquisadores, graduandos e pós-graduandos, em que foram abordadas temáticas como a "Formação do professor pesquisador na Educação Básica" e a "Alfabetização Científica".

Nos momentos seguintes, os encontros específicos ocorreram mensalmente, em um total de oito encontros, com duração de quatro horas cada. Nesses encontros, em cada grupo temático, foi realizada uma revisão do estado da arte da produção do conhecimento específico e pedagógico. Nessa etapa, os professores, coletivamente, traçaram linhas de trabalho e definiram as propostas de intervenção a serem aplicadas em sala de aula e os recursos didáticos a serem produzidos.

Foram oportunizados, nos grupos de discussão, reflexões dos professores sobre /e na sua prática, destacando suas concepções sobre ensino e aprendizagem, e propiciando a vivência de propostas inovadoras, introduzindo-os no processo de investigação dos problemas encontrados no contexto escolar, tendo em vista superar o distanciamento entre contribuições da pesquisa educacional e sua aplicação em sala de aula.

Após os quatro primeiros encontros específicos, foi realizado o terceiro momento geral, no qual, foram apresentadas as atividades desenvolvidas e propostas de intervenção elaboradas nos grupos temáticos, para a socialização do produto parcial da proposta de formação continuada.

Nos demais encontros, cada grupo temático deu continuidade às suas propostas iniciais, com a produção de vários materiais, tais como: estratégias de intervenção, projetos de pesquisa, cartilhas, laminários, jogos pedagógicos, além da produção de artigos científicos para apresentação em eventos e publicação em revistas especializadas.

Ao término do desenvolvimento da proposta, ocorreu o quarto encontro geral, no qual foram socializados os produtos construídos coletivamente, bem como alguns resultados de suas aplicações. Neste encontro foi realizada uma avaliação individual da proposta.

Está previsto um quinto encontro, para entrega do material produzido e apresentação dos projetos de pesquisa finalizados ou em andamento, ligados à proposta.

Durante todo o processo, o estabelecimento de um clima receptivo, de cooperação e confiança mútua, bem como a criação de vínculos entre os envolvidos, buscou proporcionar um espaço participativo - dar voz ao professor - mantendo o entusiasmo pelas atividades e a persistência diante dos obstáculos.

\section{Os caminhos da investigação}

A opção metodológica desta pesquisa situou-se nos domínios da abordagem qualitativa, na sua modalidade de Estudo de Caso do tipo etnográfico. Uma pesquisa do tipo etnográfico se caracteriza por apresentar, de acordo com André (2008): o princípio da interação constante entre o pesquisador e o objeto pesquisado; a ênfase no processo, naquilo que está ocorrendo, e não no produto; a preocupação com o significado, com a visão pessoal dos participantes da pesquisa, suas experiências e o mundo que as cerca, e a obtenção de uma 
Análise de uma proposta colaborativa ...

grande quantidade de dados descritivos, obtidos por meio da utilização de diferentes instrumentos de coleta, ainda que o método básico seja a observação participante.

$\mathrm{Na}$ fase inicial e durante a realização da pesquisa, desenvolvemos um estudo teórico, por meio de pesquisa bibliográfica, para aprofundamento da produção de conhecimentos relativa à formação continuada, isto é, uma revisão do estado da arte. Para o desenvolvimento da pesquisa de campo, foram realizados: observações da participação dos professores nos grupos temáticos, observações de sala de aula, questionários e entrevistas semiestruturadas.

Do nosso universo de investigação, constituído por 50 professores participantes da referida proposta de formação continuada, foi definida uma amostra de seis colaboradores, envolvidos em diferentes grupos temáticos, por percebermos que a utilização de uma parcela de professores de Ciências envolvidos na proposta nos forneceria dados significativos e aprofundados sobre o caso a ser estudado, na perspectiva da abordagem qualitativa.

A amostra foi constituída por seis educadores, que se disponibilizaram a serem colaboradores da pesquisa e apresentavam uma participação efetiva na proposta de formação continuada. Desse modo, os sujeitos da pesquisa são professoras de Ciências do Ensino Fundamental em exercício na Rede Municipal de Ensino do município de Uberlândia - MG, com idades variando entre 28 e 44 anos; tempo de atuação na área de, no mínimo, dois anos; formação específica na área de Ciências Biológicas; com pós-graduação; efetivas no cargo e atuando em séries e escolas diferentes, cujos nomes, na nossa pesquisa, são preservados e identificados pelas letras iniciais do alfabeto.

A consolidação dos dados se constituiu na realização de várias releituras das notas de campo, da tabulação das informações dos questionários e das transcrições das entrevistas, para posterior codificação dos registros, categorização e análise, orientados na perspectiva da análise de conteúdo proposta por Bardin (1977).

\section{Resultados e reflexões}

$\mathrm{Na}$ leitura qualitativa dos dados, foram constituídas categorias de análise que emergiram dos dados empíricos, dos objetivos que a pesquisa tinha em mente e do referencial teórico selecionado. Assim, como parte de uma investigação mais abrangente, que investiga vários aspectos da formação continuada de professores, neste trabalho, será realizado um recorte da pesquisa, enfocando apenas a relação entre o desenvolvimento profissional e a formação continuada, onde optamos por apresentar resultados relativos a uma das categorias construídas.

Atualmente, diferentes alternativas de formação passam a considerar aspectos que emergem da prática docente, e a conceber os professores como agentes de seu próprio desenvolvimento profissional. Nessa investigação, buscamos analisar o depoimento dos professores sobre suas aprendizagens quando submetidos a um processo formativo no qual foram vistos como práticos reflexivos - alguém que é detentor de conhecimento prévio quando acede à profissão e que vai adquirindo mais conhecimentos a partir de uma reflexão acerca de sua experiência. Foi também nosso objetivo na investigação compreender como os professores visualizam a relação estabelecida entre a formação continuada e o seu desenvolvimento profissional.

Nos estudos sobre a formação docente, muito se discute sobre o que constitui o seu desenvolvimento profissional, uma vez que é amplamente reconhecido que a formação inicial 
é insuficiente para proporcionar todos os elementos necessários para uma prática consistente (CARRASCOSA, 1996; CARVALHO; GIL-PÉREZ, 1995; SHULMAN, 1987).

O conceito de desenvolvimento profissional, conforme Marcelo (2009), tem vindo a modificar-se durante a última década, sendo essa mudança motivada pela evolução da compreensão de como se produzem os processos de aprender a ensinar, sendo considerado como um processo a longo prazo, no qual se integram diferentes tipos de oportunidades e experiências, planificadas sistematicamente para promover o crescimento docente.

De acordo com Selles (2002), há uma limitação inerente à própria natureza da formação inicial que nos leva a indagar até que ponto o recém-egresso, a despeito da qualificação outorgada pela Universidade, seria, efetivamente, um professor. Considerando-se, entretanto, que as atividades docentes, como todos os processos sociais, são marcadas pela diversidade e caracterizadas por uma dinâmica não determinística, seria impossível antecipar a experiência pedagógica aos futuros professores nos cursos de licenciatura. Portanto, parece ser consensual que o professor em exercício disponha de um programa de formação continuada que seja capaz de funcionar, não apenas como oportunidade de atualização de conhecimentos, em face das inúmeras inovações que surgem, mas, também, como elemento decodificador das práticas vivenciadas no dia a dia da sala de aula.

O professor, que, por séculos, foi visto como aquele que detinha um saber suficiente para ser transmitido aos alunos, e domínio de procedimentos metodológicos, para transmitir esses conhecimentos, passa a ser requisitado como um profissional crítico e criativo, pesquisador de sua prática, envolvido com questões político-sociais, que saiba atuar numa perspectiva de inclusão de toda diversidade cultural emergente, para concretizar os ideais de uma Educação inclusiva, democrática e participativa. Nesse sentido, impõe-se a ele que participe de atividades de formação continuada, que propiciem o seu desenvolvimento profissional e pessoal.

Assim, conforme Gama e Terrazzan (2007), ao longo de suas carreiras, os profissionais vão aceitando e participando de determinados processos de formação continuada, desde que esses processos estejam de acordo com suas próprias ideias sobre formação docente. Podemos inferir que a formação continuada se mantém, ainda, no âmbito da formação individual, mediante a qual o professor procura, de forma isolada, melhorar suas práticas de sala de aula. Quando analisamos os percursos formativos das professoras colaboradoras da pesquisa, verificamos que, além da formação inicial em Ciências Biológicas, todas elas participaram de programas de formação em serviço, como cursos de Especialização e de Mestrado, demonstrando uma preocupação com o seu crescimento profissional.

No intuito de compreendermos a percepção das professoras da pesquisa, em relação à necessidade de contínuo desenvolvimento profissional, percebemos a importância de conhecer, primeiramente, o nível de satisfação com a sua atuação docente. Nessa perspectiva, as colaboradoras da pesquisa se mostraram relativamente satisfeitas com a atividade que exercem, ressaltando algumas dificuldades, conforme os seguintes depoimentos:

"Estou feliz com a minha atuação como professora de Ciências, mas fico triste pela forma como os alunos me recebem. Tento fazer o melhor possível, mas falta muito interesse por parte deles". (professora A) 
"Estou muito feliz com a minha profissão e gosto muito da escola em que trabalho. Espero estar assim daqui a uns dez anos. Para mim, a maior dificuldade que sinto é a mudança constante de diretrizes da Educação. Formar o cidadão e trabalhar o conteúdo fica muito difícil, pois a quantidade de conteúdos na área de Ciências é muito grande. Apesar de que sempre tento aliar o conteúdo com o cotidiano do aluno. Outra dificuldade, no meu ponto de vista, é aplicar as novas tecnologias no ensino de Ciências. Ainda acho muito difícil aliar o ensino tradicional com o uso das novas tecnologias". (professora C)

"Quando penso na minha atuação como professora de Ciências, gostaria de ter mais tempo para preparar minhas aulas. Além disso, a parte burocrática também complica muito a profissão". (professora E)

"Estou satisfeita com a minha atuação como professora de Ciências, mas estou sempre buscando melhorar, mudar e repensar minha prática. Ensinar hoje em dia, em termos gerais, tem um grande problema, que é alcançar o aluno, consegui fazer o aluno se interessar". (professora F)

Quando analisamos esses depoimentos, verificamos que, apesar de estarem satisfeitas com a sua atuação profissional, as professoras demonstraram insatisfações em relação às dificuldades pertinentes ao processo ensino-aprendizagem, como: o desinteresse e a falta de motivação dos alunos para o estudo e a articulação do conteúdo ao cotidiano do aluno, além das exigências do sistema educacional, referentes ao papel do professor, ao uso das novas tecnologias no processo educativo e a parte burocrática do ensino e, ainda, a desvalorização da profissão. No entanto, notamos, em algumas colocações, a necessidade de um repensar e transformar a prática docente.

Para complementar a análise da percepção das professoras sobre a importância das ações de desenvolvimento profissional, foram obtidas, das professoras investigadas, as observações em relação aos saberes docentes necessários à prática educativa:

"Para ser um bom professor, o domínio do conteúdo específico é muito importante. Mas a adequação da linguagem ao nível cognitivo do aluno também influenciam em uma boa prática. Além disso, o professor tem que saber se relacionar com os alunos e com os colegas". (professora B)

"Só ter o domínio do conteúdo, não é suficiente para ser um bom professor, também são necessários os saberes pedagógicos e a experiência. Um professor tem que estar motivado, se ele for um professor apático, mesmo que tenha o domínio dos conhecimentos específicos, não conseguirá dar uma boa aula e despertar o interesse do aluno". (professora C) 
"O professor tem que ter, principalmente, o domínio dos conteúdos, mas precisa apresentar facilidade de se expressar para que o aluno entenda e maleabilidade para que, caso não ocorra a aprendizagem, mudar sua forma de trabalhar. Além disso, necessita ter paciência, domínio da disciplina e bom senso". (professora D)

Nessas colocações, as professoras concordam que os saberes docentes são plurais, provenientes de várias fontes, como os conhecimentos específicos, pedagógicos e experienciais, além de outros aspectos pertinentes à docência.

De acordo com diferentes teóricos, como Tardif (2002), Gauthier (1998) e Pimenta (2002), dominar o conteúdo específico não garante uma prática pedagógica eficaz. Trata-se de uma questão histórica, no sentido de que a atividade docente, durante muito tempo, foi pautada pela ênfase na transmissão de conteúdos prontos e inquestionáveis. Essa questão encontrase bastante presente no imaginário dos professores ao considerarem que o domínio do conteúdo específico é capaz de promover uma boa aula, tal como,

Nas universidades medievais, redutos únicos do saber disponível, continuou a perpetuar-se a ideia de que se ensina porque se sabe. Só mais tarde o saber sobre o como ensinar - os saberes pedagógicos e didáticos - assumiram alguma visibilidade. (ROLDÃO, 2005, p. 21)

Genericamente, os saberes disciplinares referem-se aos conhecimentos da área específica de formação, conforme Gauthier et al. (1998, p. 29), e dizem respeito "aos saberes produzidos pelos pesquisadores e cientistas nas diversas disciplinas científicas, ao conhecimento por eles produzido a respeito do mundo". Referem-se também, conforme esse autor, ao conhecimento do conteúdo a ser transmitido, uma vez que só se poderá ensinar o conteúdo que se domina. Os saberes pedagógicos estão diretamente relacionados à orientação para a prática profissional da docência, às teorias da Educação, aos processos de ensino-aprendizagem e aos princípios da organização escolar. Gauthier et al. (1998, p. 34) ressaltam que os "saberes pedagógicos são os menos desenvolvidos durante a formação dos professores o que se constitui em um problema, visto que são imprescindíveis à profissionalização do ensino."

Para compreender a percepção das professoras investigadas sobre o seu desenvolvimento profissional, analisamos as mudanças ocorridas durante a sua carreira docente, conforme explicitado em seus discursos, e como elas avaliam esse processo de transformações, por meio dos seguintes depoimentos:

"Quando comecei, eu não tinha a mínima noção do que seria a docência. Com o passar do tempo, fui adquirindo certa experiência e mudando meu ponto de vista. Eu tive que mudar porque era muito exigente comigo mesma e fiquei doente por isso. Sentia muita frustração, quando assumia o fracasso dos meus alunos como se fossem meus. Quis até largar a profissão, mas aprendi a conviver com tal sentimento. Com a experiência e a prática, consegui mudar essa realidade”. (professora A) 
Análise de uma proposta colaborativa ...

"Agora, tenho mais domínio da sala, pois no início, tinha o conhecimento específico, mas não tinha a prática, que faz toda a diferença. Saber lidar com o aluno e com os problemas disciplinares aprendi com o tempo". (professora B)

"Ao fazer um resgate da minha carreira, percebi o quanto mudei. Muitas vezes, forçada pelas exigências do sistema e outras vezes, por estar insatisfeita com a minha prática". (professora E)

Percebemos, por meio dessas colocações, que as professoras demonstraram ter vivenciado, em suas atuações, transformações em sua prática, motivadas por diversos fatores. Primeiramente, constatamos a mudança em decorrência do amadurecimento normal, cujos saberes experienciais provocaram um maior domínio da sala de aula e do conteúdo específico. Outros aspectos levantados por algumas professoras foram: a insatisfação com a prática atual, em função do sentimento de frustração pelo fracasso dos alunos, ou, ainda, as exigências do sistema educacional, o desânimo em planejar aulas diferenciadas e a nova realidade do contexto escolar, abrangendo uma grande diversidade de alunos e suas especificidades, na perspectiva de uma escola inclusiva.

Segundo Marcelo (2009), uma das ideias mais discutidas sobre formação docente refere-se àquela que afirma que as crenças que os professores já trazem consigo, quando realizam atividades de desenvolvimento profissional, afetam diretamente a interpretação e valorização que fazem das suas experiências de formação. Conforme esse autor, o modelo que está implícito na maioria dos programas de desenvolvimento profissional pretende provocar mudanças nos conhecimentos e crenças dos professores. Por sua vez, a mudança nos conhecimentos e crenças provoca uma alteração das práticas docentes em sala de aula e, consequentemente, uma provável melhoria nos resultados no processo de ensino e aprendizagem dos alunos. No entanto, os processos não funcionam dessa forma. Os professores mudam as suas crenças, não como consequência da sua participação em atividades de desenvolvimento profissional, mas vivenciando, na prática, a utilidade dessas novas práticas que se querem desenvolver. A mudança de crenças é um processo lento, que se deve apoiar na percepção de que os aspectos importantes do ensino não serão alterados com a introdução de novas metodologias ou procedimentos didáticos.

Os professores, como profissionais do ensino, desenvolvem um conhecimento próprio, produto das suas experiências e vivências pessoais, que racionalizaram e rotinizaram. De acordo com essa perspectiva, não se pode pretender que a formação inicial ofereça produtos acabados, mas, sim, compreender que é a primeira fase de um longo e diferenciado processo de desenvolvimento profissional. É necessário adotar uma perspectiva que saliente a importância da indagação e o desenvolvimento do conhecimento a partir do trabalho e reflexão dos próprios professores. Isso implica que os docentes sejam entendidos não como consumidores de conhecimento, mas como sujeitos capazes de gerar conhecimento e valorizar o conhecimento produzido por outros (GARCÍA, 1999).

As ações de desenvolvimento profissional também foram apontadas como motivadoras de transformações na prática docente, conforme algumas alegações das professoras: 
"Sempre fui muito entusiasmada, e esse entusiasmo de preparar aulas diferentes e buscar coisas novas ainda permanece. Mas há uns dois anos, comecei a ficar desanimada e insatisfeita com as minhas aulas. Foi quando resolvi participar dessa proposta de formação continuada e isso me fez reavivar a minha prática. $O$ fato de querer buscar a formação continuada já foi para mim, um sinal de que eu queria mudar”. (professora D)

"Depois da Graduação, busquei me aperfeiçoar e modificar, ao longo dos anos, minha forma de ensinar. Teve o amadurecimento normal que me ajudou a lidar melhor com os meus alunos. Os cursos dos quais participei também foram muito proveitosos. As propostas de formação continuada, vivenciadas por mim, durante minha carreira, contribuíram muito com a minha prática. Após participar dessa proposta, estou fazendo Mestrado, buscando um maior aperfeiçoamento”. (professora F)

Entre os resultados alcançados pela proposta, até o momento, passamos a indagar em que medida possibilitaram, ainda que potencialmente, um ganho profissional para os professores participantes. Que estratégias empregadas pelo projeto foram bem-sucedidas, e em que medida seriam capazes de promover o desenvolvimento profissional. As observações realizadas durante o desenvolvimentos da proposta mostraram que a participação dos professores gerou um comportamento diferenciado que os levou a buscar novas alternativas para sua prática, e a proposta passou a ter um papel aglutinador na promoção do conhecimento. Nessa perspectiva, obtivemos os seguintes depoimentos:

"As trocas de experiências ocorridas na proposta de formação continuada contribuíram para a mudança da minha prática. Não foram os temas discutidos nos encontros, mas a troca com os professores, o falar sobre o que deu certo, sobre os problemas diários. Vejo que os problemas do outro são os mesmos que os meus. E as soluções dos colegas podem me ajudar a melhorar minhas aulas". (professora A)

"Para o meu desenvolvimento profissional, penso que a melhor alternativa seria manter projetos de formação continuada como essa proposta, em que ocorra a parceria Universidade-escola, na qual, possamos produzir conhecimento, trocar experiências e inovar a prática”. (professora D)

"Quando resolvi participar dessa proposta de formação continuada, busquei o tema, no qual tinha mais deficiências de conteúdo. Buscava uma proposta de formação continuada que não fosse realizada só com palestras, mas com muita prática, de acordo com a nossa realidade de sala de aula. Acho importante voltar a ter contato com a Universidade 
Análise de uma proposta colaborativa ...

e fazer cursos de aperfeiçoamento. Quando terminamos a Graduação, nos afastamos das informações atualizadas e das inovações". (professora E)

A atualização dos conhecimentos específicos e pedagógicos e o engajamento dos professores, com vistas a uma ampliação de suas possibilidades profissionais, foram objetivos da proposta. Seu envolvimento nas discussões, sua percepção da coerência das informações, bem como o reconhecimento da validade prática dos subsídios propostos nos grupos de discussão terminaram por fazê-los reconhecer sua própria competência, aumentar sua autoestima e desejar entender suas perspectivas profissionais, conduzindo-os de volta aos ambientes universitários para o prosseguimento de sua formação docente. Dos participantes dessa proposta, cinco professores retornaram à Universidade, ingressando em programas de Pós-Graduação (lato sensu e stricto sensu).

O desenvolvimento profissional e processos de mudança são variáveis intrinsecamente relacionadas. O desenvolvimento profissional procura promover a mudança junto dos professores, para que estes possam crescer enquanto profissionais e, também, como pessoas. É uma construção do $e u$ profissional, que evolui ao longo das suas carreiras Muitas investigações se têm dedicado a tentar perceber como se dão essas mudanças e desenvolvimentos e como se constroem as aprendizagens. Sendo um processo a longo prazo, que reconhece que os professores aprendem ao longo do tempo, considera-se que as experiências são mais eficazes se permitirem que os professores relacionem as novas experiências com os seus conhecimentos prévios. Para isso, é necessário que se faça um acompanhamento adequado, indispensável para que a mudança se produza (MARCELO, 2009).

Ao contrário das práticas tradicionais de formação, que não relacionam as situações de formação com as práticas em sala de aula, as experiências mais eficazes para o desenvolvimento profissional docente são aquelas centradas na escola e que se relacionam com as atividades diárias realizadas pelos professores. Para Melo (2007), é preciso ousadia para que possamos nos desvencilhar de velhas práticas formativas que pouco contribuem para a formação de professores autônomos e conscientes da relevância social de sua profissão.

$\mathrm{Na}$ perspectiva tradicional, as ações de formação continuada que compõem o desenvolvimento profissional docente não têm ajudado os professores a modificarem sua prática por apresentarem concepções de conteúdos pedagógicos desenvolvidos por especialistas, de maneira descontextualizada da rotina de sala de aula, e sem considerar suas concepções, suas crenças e seu conhecimento experiencial. Esses saberes individuais do professor, dinamicamente desenvolvidos na prática e fortemente estabelecidos pelo tempo, filtram as novas informações e, muitas vezes, bloqueiam grande parte delas, o que caracteriza a resistência à inovação no ensino. De acordo com Gatti (2003, p. 197),

O conhecimento é enraizado na vida social, expressando e estruturando a identidade e as condições sociais dos que dele partilham. Por isso, ações sociais ou educacionais que têm por objetivo criar condições de mudanças conceituais, de atitudes e práticas precisam estar engrenadas com o meio sociocultural no qual as pessoas, que serão abrangidas por essas ações, vivem. 
As pesquisas têm reconhecido o professor como ator principal no desenvolvimento de sua prática pedagógica, como construtor e reconstrutor de conhecimentos a partir da prática conforme suas necessidades, experiências, crenças e percursos formativos e profissionais.

Assim, começou-se a resgatar o papel do professor, entendendo a complexidade da construção de sua identidade e a continuidade de sua formação profissional, que não finda na formação acadêmica inicial. Passou-se a pensar numa formação que envolvesse desenvolvimento pessoal, profissional e organizacional da profissão docente. Resgatou-se, ainda, a importância de se considerar o professor em sua própria formação, reelaborando os saberes iniciais em confronto com sua prática, a partir de um processo de reflexão. Nessa direção, apesar das diferentes tendências da formação continuada de professores, a orientação teóricoconceitual crítico-reflexiva tem sido apontada pelos diferentes estudos como a adequada (SILVA; ARAÚJO, 2005). Nesse referencial, abandona-se o conceito de formação docente como processos de atualização por meio da aquisição de informação científica e didática, descontextualizadas da prática educativa do professor, para adotar um conceito de formação que consiste em construir conhecimentos e teorias sobre a prática docente, a partir da reflexão crítica.

Quando investigados em relação à perspectiva de ações futuras de promoção do desenvolvimento profissional, os docentes pesquisados fizeram diversas referências às dificuldades relacionadas ao magistério, como: a falta de reconhecimento profissional, má remuneração salarial, pouco tempo para planejamento das aulas, falhas no sistema educacional, condições de trabalho precárias, dificuldades de formação em serviço e os problemas vivenciados no cotidiano escolar; mas realçaram o empenho pessoal e o amor à profissão como forma de superação dessas dificuldades, e enfatizaram a dimensão afetiva da mesma, como vemos nos depoimentos:

\footnotetext{
"Em primeiro lugar, a valorização profissional em termos de melhores salários, pois se o professor tem que trabalhar dois turnos, não tem tempo para se aperfeiçoar. O ideal seria que o professor tivesse tempo para a formação continuada e planejar atividades e aulas diferenciadas. Ferramentas para melhorar as aulas, nós temos, mas falta tempo para aplicá-las. Isso tudo desmotiva o professor a participar de propostas de formação continuada, falta o incentivo por parte da escola e do sistema educacional". (professora B)

"O nosso sistema educacional é muito falho. Acredito que deve acontecer uma mudança significativa no sistema, com relação à avaliação, à disciplina, ao currículo, ao funcionamento da escola, às condições de trabalho, à valorização profissional. Como posso me aperfeiçoar e dar uma melhor qualidade ao meu trabalho se preciso trabalhar dois cargos. Para mim, a formação continuada deve ter como principal foco, o professor. Trabalhar a autoestima e a parte afetiva são essenciais, não só nos aspectos profissionais, pois estamos passando por uma crise e nos sentimos desmotivados para qualquer crescimento profissional". (professora C)
} 
Análise de uma proposta colaborativa ...

"Para melhorar meu desenvolvimento profissional, a questão salarial é imprescindível. Se os salários fossem melhores, não precisaria trabalhar dois turnos e teria um tempo maior para a preparação de aulas diferenciadas, como projetos, grupos de estudos, atendimento individualizado para os alunos com dificuldade de aprendizagem. As condições de trabalho, como espaço para desenvolver atividades diferentes, a reestruturação curricular e ausência de tempo disponível para reuniões entre os professores da escola, para preparar projetos integrados são outros empecilhos para a melhoria da minha prática". (professora E)

"A formação continuada aliando o conteúdo e a metodologia de ensino poderia contribuir ainda mais com o meu desenvolvimento profissional e a reformulação da minha prática. $\mathrm{O}$ aprender a ensinar deve ser sempre constante. Precisamos estar em constante movimento, é preciso dar uma reviravolta de vez em quando, para reavivar a prática. O professor quando sai da Graduação, está cheio de ideias novas, mas não tem a experiência e o domínio de sala para aplicá-las". (professora F)

O desenvolvimento profissional e pessoal dos professores está intrinsecamente relacionado com a melhoria das suas condições de trabalho, com a possibilidade institucional de maiores índices de autonomia e capacidade de ação dos professores, individual e coletivamente. É também necessário ligar o desenvolvimento profissional aos processos formativos e ao aumento de recursos econômicos, materiais e pessoais na escola, para facilitar um crescimento profissional que se aproxime dos problemas e preocupações dos professores (GARCÍA, 1999).

Os programas de formação continuada possibilitam o desenvolvimento profissional e a atualização dos conhecimentos docentes, e, ao propiciarem reflexão crítica sobre prática, favorecem uma atuação profissional mais alinhada aos novos tempos (ANDRÉ, 2010). Conforme Nascimento (2008), a concepção de que um projeto de formação de professores não pode visar unicamente à aquisição de conhecimentos, mas, também, ao desenvolvimento do professor quanto ao conhecimento de si próprio e da realidade, implica necessariamente uma ação prolongada, baseada numa reflexão contínua e coletiva sobre todas as questões que atingem o trabalho pedagógico.

\section{Considerações finais}

A concepção dessa proposta de formação continuada tentou ir além de um simples processo de atualização por meio da aquisição de informações científicas e pedagógicas descontextualizadas da prática docente, para adotar uma concepção de formação em serviço, consistindo na construção de conhecimentos pelo professor sobre a sua prática educativa, a partir da reflexividade crítica.

A participação dos professores na proposta de formação continuada investigada começou a gerar um comportamento diferenciado que os levou a buscar novas alternativas para o seu percurso formativo. A análise da experiência realizada deixa claro que, embora, o envol- 
vimento de professores pesquisadores da Universidade como parceiros, e não, como detentores dos saberes acadêmicos específicos e pedagógicos, não tenha, no curto prazo, modificado a prática docente, contribuiu para despertar um interesse desses professores em continuar investindo em seu desenvolvimento profissional, buscando cursos de especialização e Mestrado, além da participação em eventos científicos.

Uma questão reiterada ao longo deste trabalho foi a compreensão de que a profissão docente e o seu desenvolvimento profissional constituem um elemento fundamental e crucial para assegurar a qualidade do processo ensino-aprendizagem. O estudo apontou para a necessidade de que o desenvolvimento profissional seja concebido como um processo coletivo e colaborativo, consistindo em possibilitar, aos professores, a construção de novas teorias e novas práticas pedagógicas.

\section{Referências}

ANDRÉ, M. E. D. A. de. Etnografia da prática escolar. 15. ed. Campinas: Papirus, 2008. . A pesquisa sobre formação de professores: contribuições à delimitação do campo. In: DALBEN, A. I. L. F. et al. Convergências e tensões no campo da formação e do trabalho docente. Belo Horizonte: Autêntica, 2010. p. 273-287.

BARDIN, L. Análise de conteúdo. Lisboa: Edições 70, 1977.

CANDAU, V. M. F. Formação continuada de professores: tendências atuais. In: REALI, A. M. M. R.; MIZUKAMI, M. G. N. Formação de professores: tendências atuais. São Carlos: EdUFSCar, 2007. p. 139-152.

CARRASCOSA, J. Análise da formação continuada e permanente de professores de ciências ibero-americanos. In: MENEZES, L. C. (Org.). Formação continuada de professores de ciências no âmbito ibero-americano. [Madrid]: OEI; Campinas: Autores Associados, 1996. p. 59-70.

CARVALHO, A. M. P.; GIL-PÉREZ, D. Formação de professores de ciências. São Paulo: Cortez, 1995.

FALSARELLA, A. M. Formação continuada e prática de sala de aula: os efeitos da formação continuada na atuação do professor. Campinas: Autores Associados, 2004.

GAMA, M. E.; TERRAZZAN, E. A. Características da formação continuada de professores nas diferentes regiões do país. In: REUNIÃO ANUAL DA ANPED, 30., 2007, Caxambu. Anais... Caxambu: ANPED, 2007. Disponível em: <http://www.anped.org.br/ reunioes/30ra/trabalhos/GT08-3846-Int.pdf >. Acesso em: 26 set. 2013.

GARCÍA, C. M. Formação de professores: para uma mudança educativa. Porto: Porto Editora, 1999. 
Análise de uma proposta colaborativa ...

GATTI, B. A. A formação continuada de professores: a questão psicossocial. Cadernos de Pesquisa, São Paulo, v. 1, n. 119, p. 191-204, 2003.

GAUTHIER, C. et al. Por uma teoria da pedagogia: pesquisas contemporâneas sobre o saber docente. Ijuí: Ed. da Unijuí, 1998.

IMBERNÓN, F. Formação docente e profissional: formar-se para a mudança e a incerteza. São Paulo: Cortez, 2002.

MARCELO, C. Desenvolvimento profissional docente: passado e futuro. Sísifo: revista de ciências da educação, Lisboa, n. 8, p. 7-22, jan./abr. 2009. Disponível em: <http:// sisifo.fpce.ul.pt/pdfs/revista\%208\%20PT\%20COMPL.pdf >. Acesso em: 26 set. 2013.

MELO, G. F. Tornar-se professor: a formação desenvolvida nos cursos de física, matemática e química da Universidade Federal de Uberlândia. 2007. 233 f. Tese (Doutorado em Educação) - Faculdade de Educação, Universidade Federal de Goiás, Goiânia, 2007.

NASCIMENTO, M. G. A formação continuada dos professores: modelos, dimensões e problemática. In: CANDAU, V. M. F. (Org.). Magistério: construção cotidiana. Petrópolis: Vozes, 2008. p. 69-90.

NÓVOA, A. Formação de professores e profissão docente. In: . (Coord.). Os professores e a sua formação. 3. ed. Lisboa: Dom Quixote: Instituto de Inovação Educacional, 1997. p. 15-34.

. O regresso dos professores. In: CONFERÊNCIA DESENVOLVIMENTO PROFISSIONAL DE PROFESSORES PARA A QUALIDADE E PARA A EQUIDADE DA APRENDIZAGEM AO LONGO DA VIDA, 2007, Lisboa. Comunicações... Lisboa: Ministério da Educação, 2008. p. 21-28. Disponível em: <http://www.dgae.min-edu.pt/c/ document_library/get_file?p_l_id=15446\&folderId=93067\&name=DLFE-2408.pdf. $>$. Acesso em: 26 set. 2013. (Org.). Vidas de professores. Porto: Porto Editora, 1992.

PIMENTA, S. G. Formação de professores: identidade e saberes da docência. In: PIMENTA, S. G. Saberes pedagógicos e atividade docente. São Paulo: Cortez, 2002. p. 15-34.

ROLDÃO, M. C. Saber educativo e culturas profissionais: contributos para uma construção / desconstrução epistemológica. In: CONGRESSO DA SOCIEDADE PORTUGUESA DE CIÊNCIAS DA EDUCAÇÃO, 8., 2005, Castelo Branco. Actas... Porto: Sociedade Portuguesa de Ciências da Educação, 2005. 1 CD-ROM.

SCHNETZLER, R. P. Como associar ensino com pesquisa na formação inicial e continuada de professores de ciências? In: ENCONTRO REGIONAL DE ENSINO DE CIÊNCIAS, 2., 1996, Piracicaba. Atas... Piracicaba: UNIMEP, 1996. v. 1, p. 27-35.

O professor de ciências: problemas e tendências de sua formação. In: PACHECO, R. P.; ARAGÃO, R. M. R. (Org.). Ensino de ciências: fundamentos e abordagens. Piracicaba: CAPES: UNIMEP, 2000. p. 12-41. 
Urzetta, F. C.; Cunha, A. M. O.

SCHÖN, D. Formar professores como profissionais reflexivos. In: NÓVOA, A. (Coord.). Os professores e sua formação. 3. ed. Lisboa: Dom Quixote: Instituto de Inovação Educacional, 1997. p. 79-91.

SELLES, S. E. Formação continuada e desenvolvimento profissional de professores de ciências: anotações de um projeto. Ensaio: pesquisa em educação em ciências, Belo Horizonte, v. 2, n. 2, p. 1-15, dez. 2002.

SHULMAN, L. Knowledge and teaching: foundations of the new reform. Harvard Educational Review, Cambridge, v. 57, n. 1, p. 1-22, 1987.

SILVA, E. M. A.; ARAÚJO, C. M. Reflexão em Paulo Freire: uma contribuição para a formação continuada de professores. In: COLÓQUIO INTERNACIONAL PAULO FREIRE, 5., 2005, Recife. Anais... Recife: Centro Paulo Freire de Estudos e Pesquisa, 2005. p. 1-8. Disponível em: <http://189.28.128.100/nutricao/docs/Enpacs/ pesquisaArtigos/reflexao_em_paulo_freire_2005.pdf>. Acesso em: 27 set. 2013.

TARDIF, M. Saberes docentes e formação profissional. Petrópolis: Vozes, 2002.

ZEICHNER, K. M. A formação reflexiva de professores: ideias e práticas. Lisboa: Educa, 1993.

Artigo recebido em 18/03/13. Aceito em 28/08/13. 